\title{
More than Half of Bipolar Patients attending Emanuel Mental Specialized Hospital has Poor Quality of Life, Emanuel Mental Specialized Hospital, Ethiopia: Facility- Based Cross-Sectional Study Design
}

\section{Telake Azale ${ }^{1}$, Tesfalem Araya ${ }^{2 *}$ and Elsa Melaku ${ }^{3}$}

${ }^{1}$ College of Medicine and Health Sciences, University of Gondar, Gondar, Ethiopia

${ }^{2}$ School of Nursing, College of Health Sciences, Mekelle University, Mekelle, Ethiopia

${ }^{3}$ Emanuel Mental Specialized Hospital, Addis Ababa, Ethiopia

\begin{abstract}
Background: Bipolar disorders area mental illness where changes in brain functions transform normal emotions to dramatic mood swing between mania and depression. Severity in mood swing may lead to impairment in normal social and occupational functioning. Quality of life is lower in patients' with bipolar disorder than in the general population. Poor quality of life is associated with the length of illness and lack of social support. This study was aimed at assessing the prevalence of quality of life and associated factors among people with bipolar disorder in Emanuel Mental Specialized Hospital, Addis Ababa, Ethiopia.
\end{abstract}

Methods: We employed facility based cross-sectional study among 423 bipolar patients attending Emanuel Mental Hospital from April-May 2016. We used a systematic random sampling technique to get respondents. We used Standardized, Structured and pretested questionnaire, WHO quality of life-BREF, Simpson-Angus Scale, and Morisky medication adherence screening tool was used to collect data. The collected data were coded and entered into Epi-Info3.5.3 and analyzed using SPSS version 20. A bivariate and Multivariate analysis was carried out in order to see an association between independent and outcome variables. The strength of association was interpreted using odds ratio and $95 \%$ Confidence Interval at $P$-value $<0.05$ level of significance.

Results: Four hundred eleven respondents were participated in the study making response rate of $97.1 \%$. Out of those, 240 (58.4\%) had poor-quality of life. Rural residence (AOR=1.94, 95\% Cl: 1.12-3.34), Primary education (AOR=3.08, 95\% Cl: $1.45-6.53$ ), <200 birrs monthly income (AOR $3.57,95 \% \mathrm{Cl}: 1.48-8.57$ ), $>10$ years duration of illness(AOR=3.42, 95\% Cl: 1.19-9.77), 2-4episode of illness (AOR=3.45, 95\% Cl: 1.61-7.38), and antipsychotic \& antidepressant medication( $A O R=2.15,95 \% \mathrm{Cl}: 1.04-4.45)$ were significantly associated with poor quality life

Conclusion: We found that the prevalence of a poor quality of life among bipolar patients was high. Rural residence, primary education, $<200$ birrs monthly income, $>10 y e a r s$ duration of illness, $2-4$ episode of illness, those who were on antipsychotic $\&$ antidepressant medication was significantly associated with poor quality of life. There should be continuous psycheducation and through behavioral change communication and advocacy at all levels focusing on bipolar disorder patients

Keywords: Bipolar disorder; Quality of life; Emanuel Mental Hospital; Ethiopia

\section{Introduction}

According to the WHO, quality of life is defined as individuals perceptions of their position in life in the context of their culture, value, goals, expectations, standards, and concerns. Person's physical health, psychological state, level of independence, and social relationships, to most important features of their environment were most affected quality of life (QOL) [1].

Bipolar disorders are a mental illness where changes in brain functions transform normal emotions to dramatic mood swing between mania and depression [2-4].

These results in a poor global functioning reduced quality of life and high relapse rates without treatment, patients with bipolar face substantial distress and impairment and have a significant risk of morbidity and mortality [5]. It has been associated with difficulties in work-related performance, employment, family and social interactions. This disorder was associated with an increase in lifetime health service utilization with financial difficulties, and problem in educational achievement [6].

Bipolar disorder (BD) is usually accompanied by increased morbidity and mortality that appear early in the course of the illness.
Living with a bipolar disorder has a patient can put considerable burdens and restrictions on the rest of the patients as well as among primary caregivers and their family members $[7,8]$.

The physical quality of life (QOL) is frequent and low in bipolar disorder patients than in the general population. Low QOL is also associated with increased length of illness, lack of social support $[9,10]$, reduction in health-related QOL and functional impairment even in the absence of active symptoms $[11,13]$.

Between $25 \%$ and $80 \%$ of patients fail to take their drugs correctly at some point in their treatment. Poor adherence to drugs was major

*Corresponding author: Tesfalem Araya, School of Nursing, College of Health Sciences, Mekelle University, Mekelle, Ethiopia, Tel: +251344410964; E-mail: tesfayearaya8@gmail.com

Received: July 02, 2018; Accepted: August 03, 2018; Published: August 10 2018

Citation: Azale G, Araya T, Melaku E (2018) More than Half of Bipolar Patients attending Emanuel Mental Specialized Hospital has Poor Quality of Life, Emanuel Mental Specialized Hospital, Ethiopia: Facility-Based Cross-Sectional Study Design. J Psychiatry 21: 454. doi:10.4172/2378-5756.1000454

Copyright: ( 2018 Azale G, et al. This is an open-access article distributed unde the terms of the Creative Commons Attribution License, which permits unrestricted use, distribution, and reproduction in any medium, provided the original author and source are credited 
Citation: Azale G, Araya T, Melaku E (2018) More than Half of Bipolar Patients attending Emanuel Mental Specialized Hospital has Poor Quality of Life, Emanuel Mental Specialized Hospital, Ethiopia: Facility-Based Cross-Sectional Study Design. J Psychiatry 21: 454. doi:10.4172/2378-5756.1000454

problem in patients with bipolar disorders, associated to increased rates of readmission to health institution and high treatment costs [14]. The lifetime prevalence of bipolar disorder (BD) was reported between $0-2.4 \%$ and for full bipolar spectrum between $2.6-7.8 \%[15,16]$.

The disorder has a chronic course, recurrent episodes, and high rate of mortality as well as loss of function and cognitive impairment that produce significant burden to patients' family, society and health systems [17]. Quality of life is markedly impaired even when they are considered to be clinically euthymic persons [18].

Caregivers have a high level of difficulties in interfamilial relationships and social restrictions and financial difficulties. Though much has been written on this subject among developed countries, little research has been done in developing countries particularly in Africa. Therefore, this study was assessed the prevalence and identifies factors associated with quality of life among adult bipolar patients, generate necessary data to support and guide for bipolar disorder management policies and also provide a base line for further similar studies to allow a detailed description of unique factors that facilitate or inhibit the quality of life in bipolar patients.

\section{Materials and Methods}

\section{Study design and area}

The institution-based Cross-sectional study design was employed among bipolar disorder patients attended in Emanuel Mental Hospital from April-May 2016. Emanuel Mental Specialized Hospital is located in western part of Addis Ababa in Addis Ketema sub-city kebele 08 . The Hospital was established on an area of $15,660 \mathrm{~m} 2$ with two G+1 building \&15 blocks. There are around 512 staffs. The hospital has 300 beds that serve for all type of mental disorder patients who fulfill admission criteria. The hospital serves a total of 11,115 bipolar patients per year. On average 926 patients get services per month. The hospital is working on increasing the efficiency \& effectiveness of the serves to make itself the center of mental health care excellence by giving core mental clinical services, conducting research and training and other administrative services.

\section{Sample size determination and sampling procedure}

The respondents were all bipolar disordered patients' attended in Emanuel Mental Specialized Hospital during the study period. The sample size was determined using the formula for a single population proportion based on the assumption for calculating sample size was a 95\% confidence level, $5 \%$ degree of precision and 50\% the proportion of quality of life among bipolar patient. Then by adding $10 \%$ of non-response rate, the final sample size became 423.The systematic random sampling method was used to select 423 patients from a total of 926 bipolar Adult patients who visit Emanuel Hospital. In average 926 patients visit every month, this makes the sampling fraction (k-interval) $926 / 423=2$.The first study population was selected by lottery method and study populations were chosen at regular intervals (every other patient) and the selected respondents were interviewed by data collectors.

\section{Data collection tools and quality controls}

Data were collected using standardized, structured, and pretested questionnaire. The questionnaire was first prepared in English then translated to local language (Amharic) and back-translated into
English to maintain the consistency of the questionnaire by local language translator expertise. Good quality of life was operationalized as individuals who scored greater than median on WHO QOL BREF on the whole data. Trained supervisors and data collectors participated in the data collection process from the study area who knows the culture and language of the society. Concerning the quality of life, nondrug adherent and drug side effect, WHOQOL-BREF, Non adherent and Simpson-Angus Scale respectively were used and face to face interview was employed to obtain the data.

WHOQOL-BREF contains 26 items and a sound cross-culturally valid assessment of QOL, consisting of four domains: physical health (7items), psychological health (6 items), social relationships (3 items), and environmental health (8 items); it also contains the first two questions on general perception of life and health [27].

Each individual item of the WHOQOL-BREF is scored from 1 (very dissatisfied/very poor) to 5 (very satisfied/very good). According to the instruction manual, raw scores for the domains of WHOQOLBREF were calculated and were transformed on the scale ranging from 0 to 100 , where 100 the highest and 0 the lowest QOL [28]. The median score for each domain and the total score were also calculated since the quality of life measures in studies are often presented as median.

Therefore, categorization was done using the median scores of WHOQOL-BREF. Subjects were categorized as having GOOD QOL in WHOQOL-BREF, those scores greater than or equal to the median (M) while having less than the median $(\mathrm{M})$ was categorized as poor QOL.

Drug non-adherence was also assessed using the 8 item version of a self-reporting questionnaire of Morisky medication adherence rating scale (MMARS) [29]. An extrapyramidal symptom was assessed using the 10 item version of a self-reporting questionnaire of Simpson-Angus Scale (SAS) [30]. All of the data collectors were diploma holder and have experience of data collection in a mental health survey. Two days of intensive training was given to the data collectors and supervisors on how to conduct the data collection. A brief introduction to data collectors, supervisors, and caregivers had been given before and during the collection process.

\section{Data analysis}

Each completed questionnaire was entered into Epi Info 3.5.3 statistical software and then exported to SPSS version 20.0 packages for analysis. Frequencies, proportions, and cross-tabulations were used to summarize descriptive statistics of the data. All variables which were significant at bivariate analysis were entered into multiple Logistic regression and finally, the variables which had a significant association was identified on the basis of AOR with $95 \% \mathrm{CI}$ and ap-value less than 0.05 to fit the final regression model.

\section{Results}

Four hundred eleven respondents were participated in the study making response rate of $97.1 \%$. Of those, $122(29.7 \%)$ were above 40 years of age. The mean age of the respondents was $34.34(\mathrm{SD} \pm 11.50)$ years ranging between 18- 65 years. Male were 215 (52.3\%), Orthodox 222 (54.0\%) and Amhara140 (34.1\%) by ethnicity reside in urban area accounting for 285 (69.3\%). Of the study, 218 (53.0\%) respondents were not getting married, 146 (35.5\%) had attended secondary school, $279(67.9 \%)$ were unemployed and $172(41.8 \%)$ participants fail in the first quartiles (<200birr) monthly income (Table 1$)$. 
Citation: Azale G, Araya T, Melaku E (2018) More than Half of Bipolar Patients attending Emanuel Mental Specialized Hospital has Poor Quality of Life, Emanuel Mental Specialized Hospital, Ethiopia: Facility-Based Cross-Sectional Study Design. J Psychiatry 21: 454. doi:10.4172/2378-5756.1000454

Page 3 of 6

Regarding the clinical characteristics of the respondents, 133 (32.4\%) had a duration of the illness between six and ten years, and 263(64\%) of respondents had an onset of illness before 25 years age. Of the respondents, 222(54\%) had less than two episodes per year and $344(83.7 \%)$ do not use the substance. One hundred ninety-three (47\%) study subjects were using mood stabilizer, antipsychotics and antidepressants. Of those respondents; 378 (92\%) had no drug side effects, 390(94.9\%) were adherent to the drug and (97.3\%) had no extra pyramidal symptoms.

Concerning duration of treatment, $36.3 \%$ were on treatment for one up to five years, followed by $27.7 \%$ between 6 and 10 years. One hundred thirty-four, $(32.6 \%)$ of participants feel that people treat them like an inferior because of their illness and 32.6 prefer to avoid them because of their illness (Table 2).

Regarding the WHOQOL-BREF scale, the range of scale in this study was from $40-105$ with a median value of $74 \pm 13.6$. Out of the total study participants, 240 (58.4\%) had a poor quality of life (Figure 1).

\begin{tabular}{|c|c|c|}
\hline Variables with Categories & Frequency & Percent (\%) \\
\hline \multicolumn{3}{|c|}{ Age } \\
\hline $18-24$ & 81 & 19.7 \\
\hline $25-29$ & 92 & 22.4 \\
\hline $30-34$ & 65 & 15.8 \\
\hline $35-39$ & 51 & 12.4 \\
\hline$\geq 40$ & 122 & 29.7 \\
\hline \multicolumn{3}{|c|}{ Sex } \\
\hline Male & 215 & 52.3 \\
\hline Female & 196 & 47.7 \\
\hline \multicolumn{3}{|c|}{ Religion } \\
\hline Orthodox & 222 & 54 \\
\hline Muslim & 113 & 27.5 \\
\hline Other $^{* *}$ & 76 & 18.5 \\
\hline \multicolumn{3}{|c|}{ Ethnicity } \\
\hline Amhara & 140 & 34.1 \\
\hline Oromo & 126 & 30.7 \\
\hline Guragie & 105 & 25.5 \\
\hline Others* & 40 & 9.8 \\
\hline \multicolumn{3}{|c|}{ Residence } \\
\hline Urban & 285 & 69.3 \\
\hline Rural & 126 & 3027 \\
\hline \multicolumn{3}{|l|}{ Marital status } \\
\hline Never married & 218 & 53 \\
\hline Ever married & 193 & 47 \\
\hline \multicolumn{3}{|c|}{ Educational status } \\
\hline Illiterate & 56 & 13.6 \\
\hline Primary & 136 & 33.1 \\
\hline Secondary & 146 & 35.5 \\
\hline College and above & 73 & 17.8 \\
\hline \multicolumn{3}{|c|}{ Occupation } \\
\hline Employed & 122 & 32.1 \\
\hline unemployed & 279 & 67.9 \\
\hline \multicolumn{3}{|c|}{ Monthly income } \\
\hline$\leq 200$ & 172 & 41.8 \\
\hline $201-400$ & 36 & 8.8 \\
\hline $401-600$ & 35 & 8.5 \\
\hline $601-1000$ & 77 & 18.7 \\
\hline$\geq 1000$ & 91 & 22.1 \\
\hline
\end{tabular}

Table 1: Socioeconomic and demographic factors of bipolar patients attending in Emanuel Specialized Hospital, Addis Ababa, Ethiopia; May, 2016(N=411).

\begin{tabular}{|c|c|c|}
\hline Variables with Category & Frequency(n) & Percentage (\%) \\
\hline \multicolumn{3}{|c|}{ Duration of illness } \\
\hline$<1$ year & 26 & 6.3 \\
\hline $1-5$ years & 123 & 29.9 \\
\hline $6-10$ year & 133 & 33.4 \\
\hline$>=10$ & 129 & 31.4 \\
\hline \multicolumn{3}{|c|}{ Age of onset } \\
\hline$<25$ & 263 & 64 \\
\hline $26-34$ & 95 & 23.1 \\
\hline $35-44$ & 27 & 6.6 \\
\hline$>=40$ & 26 & 6.3 \\
\hline \multicolumn{3}{|c|}{ Frequency of episode } \\
\hline$>=4$ & 33 & 8 \\
\hline 3-Feb & 97 & 23.6 \\
\hline$<2$ & 222 & 54 \\
\hline 0 & 59 & 14.4 \\
\hline \multicolumn{3}{|c|}{ Current drug use } \\
\hline Mood stabilizer & 46 & 11.2 \\
\hline antipsychotic & 64 & 15.6 \\
\hline Ant psychotic \& antidepressant & 108 & 26.3 \\
\hline $\begin{array}{l}\text { Mood stabilizer, Anti-psychotic } \\
\text { \&antidepressant }\end{array}$ & 193 & 47 \\
\hline \multicolumn{3}{|c|}{ Drug side effect } \\
\hline No & 378 & 92 \\
\hline Yes & 33 & 8 \\
\hline \multicolumn{3}{|c|}{ Duration of treatment } \\
\hline$<1$ year & 37 & 9 \\
\hline $1-5$ years & 149 & 36.3 \\
\hline $6-10$ years & 114 & 27.7 \\
\hline$>10$ years & 111 & 27 \\
\hline \multicolumn{3}{|c|}{ Substance use } \\
\hline No & 344 & 83.7 \\
\hline Yes & 67 & 16.3 \\
\hline \multicolumn{3}{|c|}{ Extra pyramidal symptom } \\
\hline No & 400 & 97.3 \\
\hline Yes & 11 & 2.7 \\
\hline \multicolumn{3}{|c|}{ Drug adherence } \\
\hline Adherence & 390 & 94.9 \\
\hline No adherence & 21 & 5.1 \\
\hline
\end{tabular}

Table 2: Clinical characteristics of bipolar patients attending in Emanuel Mental Specialized Hospital, Addis Ababa, Ethiopia; May, 2016 ( $N=411)$.

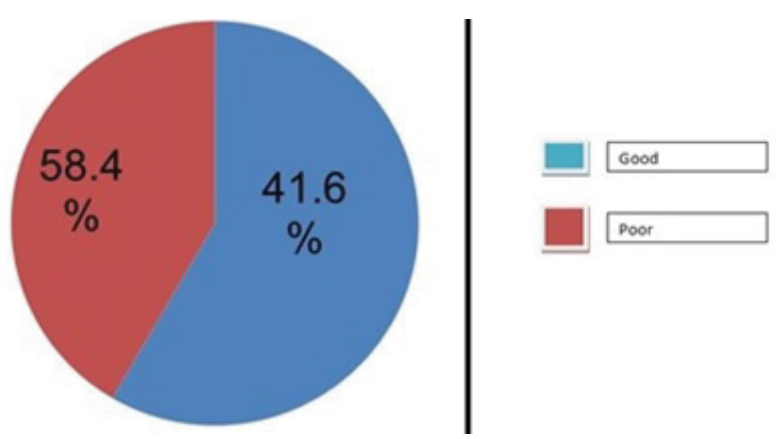

Figure 1: Overall quality of life among bipolar patients in Emanuel Specialized Mental Hospital, Addis Ababa, Ethiopia, 2016 ( $n=411)$.

The WHOQOL BREF covers four different domains of quality of life, physical, psychological, social and environmental. In this study physical, psychological, social and environmental aspects of life $56.2 \%$, 
Citation: Azale G, Araya T, Melaku E (2018) More than Half of Bipolar Patients attending Emanuel Mental Specialized Hospital has Poor Quality of Life, Emanuel Mental Specialized Hospital, Ethiopia: Facility-Based Cross-Sectional Study Design. J Psychiatry 21: 454. doi:10.4172/2378-5756.1000454

Page 4 of 6

$62.5 \%, 50.1 \%$ and $55.0 \%$ scored the poor quality of life respectively (Figure 2).

Based on bivariate analysis variables including residence, education, ethnicity, occupation, monthly income, duration of illness, the frequency of episode, duration of treatment, current drug use, substance use, marital status, religion and extrapyramidal were found to be significantly associated with quality of life. To avoid many variables and unstable estimates, only variables reached a p-value less than 0.25 at the bivariate analysis were entered into multivariate logistic regression for further analysis in order to control confounding effects.

The results of multivariate analysis showed that quality of life among bipolar patients was significantly associated with the residence, education, occupation, monthly income, duration of illness, a frequency of episode and current drug use.

It was found that residence has been significantly associated with quality of life. Being rural reside were 1.94 times (AOR=1.94, 95\% CI: 1.12-3.34) more likely had a poor quality of life as compared with urban. Respondents who learned primary education were 3 times at risk for poor quality of life ( $\mathrm{AOR}=3.08,95 \% \mathrm{CI}$ : 1.45-6.53) as compared to diploma \& above the holder.

Regarding monthly income of respondents; those who had a monthly income of $<200$ Birrs were 3.5 times at risk (AOR 3.57, 95\% CI: $1.48-8.57$ ) for a poor quality of life compared to those who had a monthly income of above 1000 Birrs.

Duration of illness was found to be significantly associated with poor quality of life. Respondents who had 10 years and above duration of illness were about 3 times more likely to be affected ( $\mathrm{AOR}=3.42,95 \%$ CI: 1.19-9.77) compared to those who had less than one year of duration of illness. Respondents who had more than 2 episodes were about 3 times more likely affected on their quality of life (AOR=3.45, 95\% CI: 1.61-7.38) as compared to those with no episode. Current medication use was also significantly associated with poor quality of life among bipolar patients. Those patients with antipsychotic and antidepressants were found to be about 2 times more likely affected as to their quality of life than those with the only mood stabilizer (AOR=2.15, 95\% CI: 1.04-4.45) (Table 3).

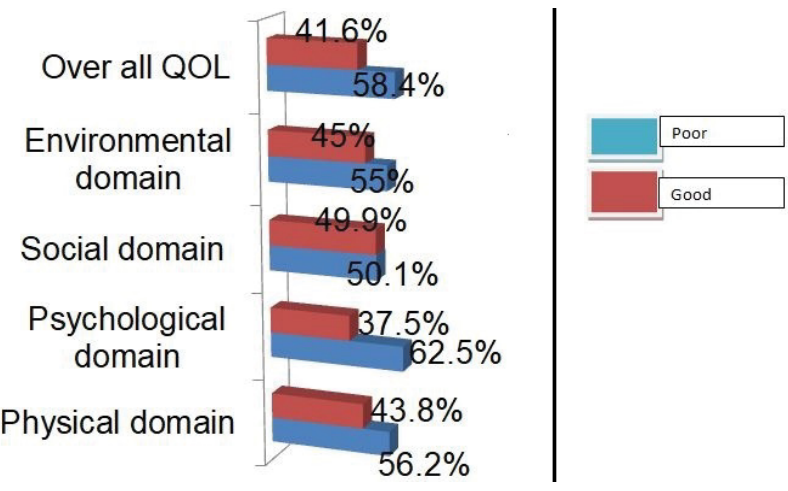

Figure 2: Distribution of four domains of WHO QOL-BREF among bipola patients in Emanuel Specialized Mental Hospital, Addis Ababa, Ethiopia, 2016 $(n=411)$.

\begin{tabular}{|c|c|c|c|c|}
\hline \multirow{2}{*}{ Variable } & \multicolumn{2}{|c|}{ Quality of life } & \multirow{2}{*}{ COR $95 \% \mathrm{Cl}$} & \multirow{2}{*}{ AOR $95 \% \mathrm{Cl}$} \\
\hline & Poor & Good & & \\
\hline \multicolumn{5}{|c|}{ Residence } \\
\hline Rural & 76 & 50 & $1.73(1.132-2.66)^{\star *}$ & $1.94(1.12-3.34)^{\star *}$ \\
\hline Urban & 133 & 152 & 1 & 1 \\
\hline \multicolumn{5}{|c|}{ Education } \\
\hline No formal education & 34 & 22 & $3.36(1.62-6.96)^{\star * *}$ & $2.06(0.83-5.11)$ \\
\hline Primary education & 82 & 54 & $3.3(1.80-6.02)^{\star \star *}$ & $3.08(1.45-6.53)^{\star * *}$ \\
\hline Secondary education & 70 & 76 & $2.00(1.11-3.61)$ & 1.63(0.81-3.28) \\
\hline Diploma and above & 23 & 50 & 1 & 1 \\
\hline \multicolumn{5}{|c|}{ Occupation } \\
\hline Jobless & 98 & 87 & 1.57(0.94-2.6) & $0.47(0.20-1.13)$ \\
\hline Daily labor & 43 & 16 & $3.7(1.84-7.61)^{\star * *}$ & $1.81(0.69-4.7)$ \\
\hline Farmer & 16 & 19 & $1.2(0.53-2.57)$ & $0.28(0.10-0.81)$ ** \\
\hline Merchant & 4 & 27 & $0.72(0.33-1.55)$ & 0.4(0.16-1.00) \\
\hline Government employ & 38 & 53 & 1 & 1 \\
\hline \multicolumn{5}{|c|}{ Monthly income } \\
\hline$<200$ & 102 & 70 & $3.1(1.82-5.32)^{\star * *}$ & $3.57(1.48-8.57)^{* * *}$ \\
\hline $200-400$ & 23 & 13 & $3.78(1.68-8.50)^{\star * *}$ & $1.83(0.65-5.15)$ \\
\hline $401-600$ & 23 & 18 & $2.26(1.02-5.02) *$ & $1.09(0.39-3.03)$ \\
\hline $601-1000$ & 23 & 40 & $1.97(1.05-3.70)$ & $1.21(0.58-2.55)$ \\
\hline$>1000$ & 29 & 62 & 1 & 1 \\
\hline \multicolumn{5}{|c|}{ Duration of illness } \\
\hline$<1$ year & 7 & 19 & 1 & 1 \\
\hline $1-5$ years & 57 & 66 & $2.65(0.10-0.67)$ *** & $1.83(0.64-5.22)$ \\
\hline $6-10$ years & 70 & 63 & $0.62(0.37-1.02)$ & 2.62(0.92-7.49) \\
\hline$>10$ years & 75 & 54 & $0.80(0.49-1.30)$ & $3.42(1.19-9.77)^{* * *}$ \\
\hline \multicolumn{5}{|c|}{ Frequency of episode } \\
\hline$>4$ & 20 & 13 & $2.58(1.07-6.20)$ & $2.26(0.84-6.11)$ \\
\hline 4-Feb & 67 & 30 & $3.75(1.9-7.42) * * *$ & $3.45(1.61-7.38) * * *$ \\
\hline$<2$ & 100 & 122 & $1.37(0.76-2.48)$ & $1.47(0.75-2.87)$ \\
\hline 0 & 22 & 37 & 1 & 1 \\
\hline \multicolumn{5}{|c|}{ Current drug use } \\
\hline Mood stabilizer & 25 & 21 & 1 & 1 \\
\hline Anti-psychotic & 31 & 33 & $0.78(0.36-1.68)$ & $1.39(0.58-3.28)$ \\
\hline $\begin{array}{c}\text { Anti-psychotic \& anti- } \\
\text { depressant }\end{array}$ & 74 & 34 & $1.82(0.90-3.71)$ & $2.15(1.04-4.45)^{\star}$ \\
\hline $\begin{array}{l}\text { Anti-psychotic, anti- } \\
\text { depressant \&Mood } \\
\text { stabilizer }\end{array}$ & 79 & 114 & $0.58(0.30-1.11)$ & $0.63(0.33-1.21)$ \\
\hline $\begin{array}{l}\text { N.B.P-value }<0.05 \text { repr } \\
\text { association on multivar } \\
{ }^{* * *} \text { P-value }<0.001,{ }^{* *}\end{array}$ & esents & riables & $\begin{array}{l}\text { that have statistically } \\
p-\text { value }<0.05\end{array}$ & significant \\
\hline
\end{tabular}

Table 3: Association of Socio-economical and demographical factors among bipolar patients attending at Emanuel specialized mental hospital, Addis Ababa, Ethiopia; 2016( $n=411)$.

\section{Discussion}

Bipolar Disorder has a chronic course, recurrent episodes, and high rate of mortality as well as loss of function and cognitive impairment that produce significant burden to patients' family, society and health systems [17]. The underlying reason for using QOL measures in clinical practice is to ensure that treatment plans and evaluations focus on the patient rather than the disease. Therefore this hospitalbased cross-sectional study was conducted to assess the quality of life and associated factors by using WHOQOL- BREF, extrapyramidal symptom was assessed by using Simpson-Angus Scale and Morisky medication adherence screening was also used to assess drug adherent.

In this study, the WHO QOL-BREF showed that bipolar patients were significantly associated in poor quality of life in physical domain (56.2\%), psychological domain (62.5\%), social domain $(50.1 \%)$ and 
Citation: Azale G, Araya T, Melaku E (2018) More than Half of Bipolar Patients attending Emanuel Mental Specialized Hospital has Poor Quality of Life, Emanuel Mental Specialized Hospital, Ethiopia: Facility-Based Cross-Sectional Study Design. J Psychiatry 21: 454. doi:10.4172/2378-5756.1000454

environmental domain (55.0\%) which was consistent to other study findings [21,24-26].

This study finding revealed that bipolar patients who lived in rural areas were about 1.94 times more affected in terms of their quality of life than those who lived in urban areas. This study is in line with a study conducted in Norway and other areas $[23,25]$. The result could be mainly due to a poor mental health service and low awareness of mental illness in rural settings than in urban areas.

This study revealed that education was a determinant factor for quality of life. Primary education was about 3 times more likely affected in their quality of life as compared to patients with a diploma and above education level. This is similar to a study conducted in Canada and Norway [22,25]. This might be due to an influence of education; that is an individual with high level of education might have the ability to think critically than those who are with the low level of education. In other words, increasing educational level can improve awareness and health seeking behavior of patients which contribute to good quality of life.

The monthly income of the respondent had a significant association with quality of life. Participants who had less than 200 Birr monthly incomes were 3.5 times more affected than those who earn more than Birr 1000 per month [AOR=3.57 95\% CI:1.48-8.57]. This is related to other studies $[19,20]$.The result could be mainly due to the fact that those with better monthly income can access and afford health services which later contribute to improving quality of life.

Duration of illness, the frequency of episode, and the age of onset, current drug use, drug side effect, and the duration of treatment, substance use, extrapyramidal symptom and drug adherence are common clinical factors affecting the quality of life of the bipolar patient. This is similarly related to other studies [16,21]. The result could be mainly due to the fact that those with long duration of illness can have a chance to lose their job, social interaction, unable to manage their overall life and increase the frequency of episode. This may be the absence of mood stabilizer will result in increased frequency of episode and couldn't revive easily from illness. A bipolar patient may stay with only mood stabilizer drugs for a relatively long period of time than other drugs.

In our study sex of the patient was not significantly associated with quality of life. But study did in USA show females had lower quality of life than males [31].

This difference could be due to the difference in socio cultural issues and difference in coping mechanisms.

Age of the participants was not significantly associated with quality of life. This study was in line with study done in UK. Participants with higher educational attainment appeared to have good quality of life [2232]. People with bipolar disorder have poor quality of life than the general population which is in line with study done in pristine, England [33].

The investigator does not assess quality of life between the sub types of bipolar disorder. So we did not differentiate whether their quality of life differs or no. This is the limitation of this study.

\section{Conclusion}

This study revealed that poor quality of life was found to be high on bipolar patients. In conclusion, low level of educational status, low monthly income, high duration of illness, high frequency of episode and current drug use were significantly associated with poor quality of life. Health facilities should have trained mental health professionals.
Promote ongoing skill-based health information dissemination to increase awareness of the community on mental health in general and bipolar disorder in particular. Provide occupational therapy to bipolar patients like income generating activities. Emphasis should be given in follow up of patients with appropriate management. Further prospective Cohort and mixed study should be conducted regarding the quality of life in the different sub types of bipolar disorders.

\section{Acknowledgement}

Authors' gratitude goes to The University of Gondar College Health Sciences and Medicine and Emanuel Mental Specialized Hospital for financial support. The funder had no role in study design, data collection, analysis and decision to publish We would like to thanks the study subjects for their willingness to participate in the study. Last but not least our heartfelt thank go to the supervisors and data collectors for their admirable endeavor during the data collection.

\section{Conflict of Interest}

None

\section{Reference}

1. Murray CJ, Lopez AD, Jamison DT (1994) The global burden of disease in 1990: summary results, sensitivity analysis and future directions. Bull World Health Organ 72: 495-509.

2. Mahmood KT, Akram SK, Razzaq UA, Haq IU, Tahir M (2011) management of bipolar disorder (BD) through medication at public sector hospital in lahore. $J$ Pharm Sci Res 3: 1491-1498.

3. DSM-IV-TR (2000) Diagnostic and Statistical Manual of Mental disorders.

4. Macklin P, Young AH (2004) Rapid cycling bipolar disorder: historical overview and focus on emerging treatments. Bipolar Disord 6: 523-529.

5. Dilnawan P, Ziyaurahaman AR, Bhise KS (2010) Bipolar disorder: Review. Int J Res Ayur Phar 1: 327-331.

6. Shabani A, AsI MA, Zangeneh K, Teimurinejad S, Kokar S (2013) Quality of Life in Patients with Bipolar I Disorder. Acta Medica Iranica 51: 386-393.

7. Weber NS, Cowan DN, Bedno SA, Niebhur DW (2010) Descriptive Epidemiology of Bipolar I Disorder Among United States Military Personnel. Military Medicine 175: 247

8. kausalk P, Bhatia MS (2013) Burden and Quality of life in spouses of patients with schizophrenia and bipolar disorder. Delhi Psy j 16: 1

9. WHO (1997) WHOQOL life Instruments Geneva. Division of Mental Health and prevention of substance Abuse Measuring Quality of life.

10. Rojas LG, Gurpegui M, Ayuso-Mateos JL, Gutiérrez-Ariza JA, Ruiz-Veguilla M Jurado D (2008) Quality of life in bipolar disorder patients: a comparison with a general population sample. Bipolar Disord 10: 625-634

11. Dean BB, Gerner D, Gerner RH (2004) A systematic review evaluating healthrelated quality of life, work impairment, and health-care costs and utilization in bipolar disorder. Curr Med Res Opin 20: 139-154.

12. Michalak EE, Yatham LN, Lam RW (2005) Quality of life in bipolar disorder: a review of the literature. Health and Quality of Life Outcomes 3: 72.

13. Yatham LN, Lecrubier Y, Fieve RR, Davis KH, Harris SD, et al. (2004) Quality of life in patients with bipolar I depression: data from 920 patients. Bipolar Disord 6: 379-385

14. Priebe S, Yeeles K, Bremner S, Lauber C, Eldridge S, et al. (2013) Effectiveness of financial incentives to improve adherence to maintenance treatment with antipsychotics. 347: 1136.

15. Faravelli C, Rosi S, Alessandra Scarpato M, Lampronti L, Amedei SG, et al. (2006) Threshold and subthreshold bipolar disorders in the Sesto Fiorentino Study. J Affect Disord 94: 111-119.

16. Kessler RC, Berglund P, Demler O, Jin R, Merikangas KR, et al. (2005) Lifetime prevalence and age-of onset distributions of DSM-IV disorders in the National Comorbidity Survey Replication. Arch Gen Psychiatry 62: 593-602.

17. Reinares M, Vieta E, Colom F, Martínez-Arán A, Torrent C, et al. (2006) Sánchez-Moreno J. What really matters to bipolar patients' caregivers: Sources of family burden? J Affect Disord 94: 157-163. 
Citation: Azale G, Araya T, Melaku E (2018) More than Half of Bipolar Patients attending Emanuel Mental Specialized Hospital has Poor Quality of Life, Emanuel Mental Specialized Hospital, Ethiopia: Facility-Based Cross-Sectional Study Design. J Psychiatry 21: 454. doi:10.4172/2378-5756.1000454

Page 6 of 6

18. Sierra P, Livianos L, Rojo L (2005) Quality of life for patients with bipolar disorder: relationship with clinical and demographic variables. data from 920 patients. 7: 159-165

19. Ware JE, Snow KK, Kosinski M, Gandek B (1993) Health Survey: Manual and interpretation guide, Boston, MA, the health institute.

20. Zhang H, Wisniewski SR, Bauer MS, Sachs GS, Thase ME (2006) Comparisons of perceived quality of life across clinical states in bipolar disorder: data from the first 2000 Systematic Treatment Enhancement Program for Bipolar Disorder (STEP-BD) participants. Compr Psychiatry 47: 161-168.

21. Altman S, Haeri S, Cohen LJ, Ten A, Barron E (2006) Predictors of Relapse in Bipolar Disorder: A Review. Psychiatric Practice 12: 269-282.

22. Awad AG, Kritrika R, Bolge SC, McDonnell DD (2007) Quality of life among bipolar patients misdiagnosed as with major depressive disorder. Prim Care Companion J Clin psychiatry 9: 195-202.

23. Shrut S, Bhatia MS, Sharma V, Rajender G, Kumar P (2010) Health-Related Quality of Life in Bipolar Disorder Patients and Their Caregivers. Inter J Men Health. 39: 3-15.

24. Amini H, Sharifi V (2012) Quality of Life in Bipolar Type I Disorder in a OneYear Followup. Depression Res Treat 860745: 11.

25. Lagerberg TV, Andreassen OA, Ringen PA, Berg AO, Larsson S, et al. (2010) Excessive substance use in bipolar disorder is associated with impaired functioning rather than clinical characteristics, a descriptive study. BMC Psychiatry 10: 9 .
26. Gutiérrez-Rojas L, Gurpegui M, Ayuso-Mateos JL, Gutiérrez-Ariza JA, RuizVeguilla M, et al. (2008) Quality of life in bipolar disorder patients: a comparison with a general population sample. Bipolar Disord 10: 625-634.

27. Bonomi AE, Patrick DL, Bushnell DM, Martin M (2000) Validation of the United States' version of the World Health Organization Quality of Life (WHOQOL) instrument. J Clin Epidemiol 53: 1-12.

28. WHO (1998) Division of Mental Health and Prevention of Substance Abuse: WHOQOL User Manual. Geneva, Switzerland.

29. Morisky DE, Ang A, Wood MK, Ward HJ (2008) Predictive Validity of A Medication Adherence Measure in an Outpatient Setting. J Clin Hypertens 10: 348-354.

30. Chouinard G, Margolese HC (2005) Manual for the Extrapyramidal Symptom Rating Scale (ESRS). Scizophr Res 76: 247-265.

31. Sylvia LG, Montana RE, Deckersbach T, Thase ME, Tohen M, et al. (2017) Poor quality of life and functioning in bipolar disorder. Int J Bipolar Disorder 5:10.

32. Lee Mortensen G, Vinberg M, Lee Mortensen S, Balslev Jørgensen $M$, Eberhard J (2015) Bipolar Patients' Quality of Life in Mixed States: A Preliminary Qualitative Study. Psychopathology 48:192-201.

33. Award AG, Rajargopalan K, Bolge SC, Mc Donnel DD (2007) Quality of life among bipolar disorder patients misdiagnosed with Major Depressive Disorder. Prime Care Companion J Clin Psychiatry 9:195-202. 